\title{
Chronic smokeless tobacco consumption contributes to the development of renal diseases in the human male volunteers
}

\begin{abstract}
Smokeless tobacco may able to induce microalbuminuria. The present study investigates the relation between nicotine and cotinine with renal function in gutkha and khaini users. Methods: The levels of nicotine and cotinine were estimated by HPLC methods and other urine variables were detected by spectrophotometric methods. Current smokeless tobacco users have shown that significantly elevated levels of nicotine, cotinine, and epinephrine excretion in the urine than non-tobacco users. Renal function was assessed by glomerular filtration rate (GFR), levels of urea, and creatinine. Among the kidney function measures that we examined, microalbuminuria, decreased glomerular filtration rate, and creatinine clearance were found associated with gutkha and khaini users. Significantly decreased proteinuria, urea and increased levels of uric acid and creatinine excretion with the concomitant increase in plasma total proteins, urea, and decreased uric acid levels were observed in the group I and group II users compared to group III users. The products of smokeless tobacco are regarded as good predictors of assessing the free radical levels in the cells. The active markers of nitroxidative stress have been elevated progressively with the uptake of nicotine and exposure. The nicotine and cotinine were significantly positive correlated with renal markers (creatinine, urea, and GFR), nitric oxide, malondialdehyde, and epinephrine. Increased excretion of nicotine and epinephrine indicated that the renal related complications may occur. The smokeless tobacco products were significantly and directly proportional to the levels of kidney dysfunction.
\end{abstract}

Keywords: albuminuria, cotinine, glomerular filtration rate, nicotine, renal diseases
Volume 7 Issue 6 - 2018

\author{
S Fareeda Begum,' G Nagajothi, ${ }^{2} \mathrm{~K}$ \\ Swarnalatha,' C Suresh Kumar,' Narendra \\ Maddu' \\ 'Department of Biochemistry, Sri Krishnadevaraya University, \\ India \\ ${ }^{2}$ Department of Corporate Secretaryship, Queen Mary's \\ College (Autonomous), India
}

\section{Correspondence: Narendra Maddu,Assistant Professor, Department of Biochemistry, Sri Krishnadevaraya University, Ananthapuramu-5 I5003, Andhra Pradesh, India, Tel $91+$} 944|983797, Email dr.narendrameddu@gmail.com

Received: June 01, 2018 | Published: November 26, 2018

\section{Abbreviations: SLT, smokeless tobacco; MDA, malondialdehyde; CKD, chronic kidney disease; iNOS, inducible nitric oxide synthase; GFR, glomerular filtration rate}

\section{Introduction}

Tobacco is consumed mainly in two forms named as smoking tobacco and smokeless tobacco. ${ }^{1}$ The smokeless tobacco (SLT) consumption is greatly prevalent in at least 70 low, middle and high income countries, consumed by more than 300 million people. ${ }^{2}$ Smokeless tobacco is ingested as chewing, sucking and through the nasal mucosa, but not smoked. Smoking bans in public places has increased, the consumption of smokeless tobacco has risen as an alternative source of cigarettes. ${ }^{3}$ Smokeless tobacco products are available in Indian market in multiple forms like khaini, gutkha, mawa, panmasala with tobacco, betel containing lime, catechu, zarda, and dry leaves of tobacco. ${ }^{4}$ Nicotine is major alkaloid and acts as drug specific present in the leaves of Nicotiana tubacum tertiary amine consists of pyridine and a pyrrolidine rings. ${ }^{5}$ The major portion of metabolism in nicotine is convert the cotinine and 3-hydroxycotinine in smoker users. ${ }^{6,7}$ Different people convert different percentage of nicotine to cotinine and metabolize cotinine differently at different rates. ${ }^{8}$ Cotinine acts as a marker of nicotine exposure and a major metabolite and its detection is performed in blood, saliva and urine samples. Smokeless tobacco products could promote the production of oxygen derived free radicals that enhance the higher rates of lipid peroxidation. Urinary malondialdehyde is one of the products of lipid peroxidation process and used as a marker of oxidative stress. The reactive nitrogen species include nitric oxide and peroxynitrites with active groups disrupts and damage the DNA and proteins in the cells. ${ }^{9}$ The adverse effects of smokeless tobacco on renal function have gained more attention. Uric acid is the end product of purine metabolism in blood and marked it acts as an early sign of kidney injuries. ${ }^{10}$ Oral intake of tobacco by chewing also increased the excretion as nicotine which can be absorbed from oral mucosa. ${ }^{11}$ Urinary excretion of nicotine and cotinine can be used as an index of smokeless tobacco consumption and prevalence. Urinary albumin is a sensitive marker of glomerular injury and microalbuminuria indicates renal damage induced by smokeless tobacco. The aim of the present study was to determine the excretion of nicotine and cotinine in the urine of gutkha and khaini users and their relationship with renal complications.

\section{Materials and methods}

\section{Chemicals}

Nicotine with purity of $\geq 99 \%$ and cotinine with purity of $98 \%$ was used as internal standards for analysis by HPLC method. Standard epinephrine, Methanol, Dichloromethane, Diethyl ether, Acetonitrile, Sodium n-Heptane sulponic acid, Potassium dihydrogen phosphate $\left(\mathrm{KH}_{2} \mathrm{PO}_{4}\right)$, Ammonium acetate and Acetic acid (HPLC grade), N-1naphthylethylene diamine (NED), Trichloroacetic acid (TCA), Thiobarbituric acid (TBA) and all other fine chemicals were purchased from Sigma Aldrich, Bangalore. 


\section{Study area and data collection}

Ninety human male volunteers were included in this study. The entire studied population was subdivided into three groups: Gutkha and khaini users are the experimental groups which include mainly auto drivers, car mechanics and house builders by using a questionnaire and the control group or non-tobacco users, individuals who do not consume any form of tobacco were enrolled in this study. The inclusion criteria are the habitual use of only gutkha and khaini packets by the gutkha and khaini users respectively, and the unmarried and low economic status people were chosen. The exclusion criteria are the consumed either alcohol or smoking groups or religious of the people are not preferred. Each group consisted of thirty volunteers and the baseline information for the category of SLT users was that individuals used smokeless tobacco products habitually, at least 5 times of $4-5 \mathrm{~g}$ per day for 4 years. This study was approved by the Institutional Ethical Committee.

\section{Group I - Gutkha users}

Group II - Khaini users

Group III- Normal controls.

\section{Urine collection and analysis}

First urine samples in morning were collected in a sterile flask covered with aluminium foil to keep out stray light and processed within $2 \mathrm{~h}$ of the collection. The collected samples were centrifuged at $2000 \mathrm{~g}$ for $10 \mathrm{~min}$ for further analysis.

\section{Biochemical estimations}

The concentrations of nicotine, cotinine and epinephrine in urine samples were estimated by HPLC method. Spectrophotometric methods were used to determine the levels of creatinine, lipid peroxiation and nitric oxide (nitrite and nitrates). Total proteins, albumins, urea and uric acid levels were estimated by auto analyzer kit methods. Glomerular filtration rate (GFR), urea clearance, creatinine clearance, albumin creatinine ratio and protein creatinine ratio were calculated.

\section{Determination of creatinine (Cr)}

Creatinine was determined according to the spectrophotometric method of Jaffe's which is based on the reaction of creatinine with picric acid in alkaline $\mathrm{pH}$ described by the method of Varley et al. ${ }^{12}$

\section{Determination of nitrites and nitrates}

Nitrites levels in urine were estimated as described by the method of Sastry et al. ${ }^{13}$ Urine samples were deproteinized by adding $30 \%$ $\mathrm{ZnSO}_{4}$ followed by centrifugation at $10,000 \mathrm{~g}$ for $5 \mathrm{~min}$. Then $1 \mathrm{ml}$ of plasma supernatant was mixed with $1 \mathrm{ml}$ of Gries reagent $(1 \mathrm{~g} /$ lit sulfanilamide, $25 \mathrm{~g} / \mathrm{lit}$ phosphoric acid and $0.1 \mathrm{~g} / \mathrm{lit} \mathrm{N}-1$ naphthylethylene diamine) and the absorbance was measured at 540 $\mathrm{nm}$ and results are expressed as $\mu$ moles/g creatinine.

For the determination of nitrates urine was mixed with activated cadmium filings were washed 3 times with distilled water and swirled for 1 to $2 \mathrm{~min}$ in $5 \mathrm{mM} \mathrm{CuSO}$ solution in glycine- $\mathrm{NaOH}$ buffer and then incubated at room temperature for $90 \mathrm{~min}$, with thorough shaking. After incubation, cadmium fillings were removed and the reduced nitrite levels were estimated by using Gries reagent as described earlier. The values obtained by this procedure represent the sum of nitrite and nitrate levels in the form of nitric oxide (NO).

\section{Determination of lipid peroxidation}

The extent of lipid peroxidation was measured by the formation of malondialdehyde (MDA) by the method of Buege..$^{14}$ One millilitre of urine was taken in a test tube to which $2 \mathrm{ml}$ of reagent $(15 \% \mathrm{w} / \mathrm{v}$ TCA, $0.375 \% \mathrm{w} / \mathrm{v}$ TBA and $0.25 \mathrm{~N} \mathrm{HCl}$ ) was added and kept in boiling water bath for $15 \mathrm{~min}$ and the contents were allowed to cool and then centrifuged at $1000 \mathrm{~g}$ for $10 \mathrm{~min}$. The supernatant was transferred into a separate test tube and the absorbance of the sample was read at $535 \mathrm{~nm}$ by a UV-Visible spectrophotometer against the reagent blank assuming the molar extinction coefficient to be $1.56 \mathrm{X} 10^{5}$.

\section{HPLC}

HPLC system (Shimadzu, Japan) is equipped with a binary gradient system with variable UV/VIS detector (SPD-20A) and Rheodyne injector with a $20 \mu \mathrm{l}$ loop and LC-20AD pumps and integrator. Reversed phase chromatographic analysis was performed in isocratic condition using $\mathrm{C} 18$ reverse phase column $(5 \mu)$ at $37^{\circ} \mathrm{C}$.

\section{HPLC operating conditions of nicotine and cotinine}

Resolution of peaks was performed with the mobile phase consisting a mixture of $0.272 \mathrm{~g}$ of $\mathrm{KH}_{2} \mathrm{PO}_{4}, 0.184 \mathrm{~g}$ of sodium $\mathrm{n}$-heptane sulfonate, $820 \mathrm{ml}$ of water (HPLC-grade), and $180 \mathrm{ml}$ of methanol (HPLC grade). The $\mathrm{pH}$ of the mobile phase was adjusted by drop wise addition of ortho phosphoric acid $(\mathrm{pH}=3.2)$. The flow rate used was $1.0 \mathrm{ml} / \mathrm{min}$, and the wavelength was fixed at $256 \mathrm{~nm}$ for nicotine and $262 \mathrm{~nm}$ for cotinine as per the modified method of Massadeh et al. ${ }^{15}$ Nicotine and cotinine at the concentration of $20 \mu \mathrm{M} /$ $\mathrm{ml}$ were used as standards.

\section{Sample analysis of nicotine and cotinine}

Sample analysis was processed by the modified method of Massadeh et al. ${ }^{15}$ An aliquot of urine $(0.1 \mathrm{ml})$ was placed into a glass test tube was alkalinized with $20 \mu \mathrm{l}$ of $5.0 \mathrm{M} \mathrm{NaOH}$, vortex mixed at $2800 \mathrm{rpm}$ for 30s. Equal amounts of dichloromethane-diethyl ether $(1: 1 \mathrm{v} / \mathrm{v})$ and were used for one-step single extraction, and then vortex mixed at $2800 \mathrm{rpm}$ for $2 \mathrm{~min}$. The organic layer, after centrifugation at $3500 \mathrm{rpm}$ for $3 \mathrm{~min}$, was transferred to a new glass tube containing $4 \mu 1$ of $0.25 \mathrm{M} \mathrm{HCl}$. The organic phase was then evaporated under a stream of nitrogen at $35^{\circ} \mathrm{C}$ until dryness and reconstituted in $50 \mu 1$ of mobile phase. An aliquot of $20 \mu 1$ was injected into the HPLC for analysis.

\section{HPLC operating conditions of epinephrine}

Resolution of peaks was performed with the mobile phase composed of a mixture of acetic acid and $50 \mathrm{mM}$ ammonium acetate buffer $\mathrm{pH}$ at $3.1(1: 99 \mathrm{v} / \mathrm{v})$. The flow rate used was $1.0 \mathrm{ml} / \mathrm{min}$, and the wavelength was fixed at $285 \mathrm{~nm}$ for epinephrine as per the modified method of Misra et al. ${ }^{16}$ Epinephrine concentrations of $1 \mathrm{mg} / 1 \mathrm{ml}$ were used as stock solution.

\section{Statistical data analysis}

All the quantitative data were expressed as mean \pm SEM and Students t-test was used to determine the significance of the parameters between the groups and the Pearson correlation coefficient was analyzed using Graph Pad Prism version 6.01 for Windows. $P<0.05$ was considered statistically significant. 


\section{Results}

\section{Concentrations of nicotine, cotinine, and epinephrine in urine}

Our data demonstrated that the concentration of nicotine and cotinine excreted found that the significantly increased excretion in the urine of smokeless tobacco subjects than non-user control subjects. The smokeless tobacco consumers had significantly elevated levels of epinephrine in comparison with the non-consumers (Figure 1).

\section{Urine biochemical profile}

We found that significantly decreased levels of total proteins (Gutkha users, $-27.40 \%$ and khaini users, $-28.88 \%$ ) and globulins in urine of gutkha and khaini consumers in comparision with controls. Urinary albumin levels were increased in group I (25.00\%) and group II $(6.25 \%)$ users than group III users. Gutkha consumers had significantly higher levels of uric acid, while khaini users showed elevated levels of uric acid with no significant change when compared to non-chewers control subjects. The mean urea levels decreased in smokeless tobacco users (group I, $-8.57 \%$ and group II, $-10.66 \%$ ) with no significant difference with non-tobacco chewers. The smokeless tobacco users exhibited that significantly increased levels of creatinine in plasma and urine compared to non-tobacco users (Figure 2).
The levels of protein creatinine ratio are diminished in smokeless tobacco users with no significant change in comparison with nonusers. The group I and group II users had diminished levels of urea clearance and there was a statistically significant difference in group I users but not in group II users than normal controls. The levels of creatinine clearance and glomerular filtration rate were decreased and the difference between the GFR and creatinine clearance of the two experimental groups was not statistically significant with the normal healthy controls (Figure 3).

\section{Levels of nitroxidative stress parameters}

The mean concentrations of total nitric oxide were significantly elevated in gutkha users and khaini users with no significant difference as compared to non-tobacco users. Smokeless tobacco consumers exhibited that significantly raised levels of malondialdehyde in the urine compared to non-chewers. The albumin creatinine ratio (ACR) was decreased and ACR values of the two experimental groups were not statistically significant with the non-tobacco users (Figure 4). Plasma total proteins and globulins were increased whereas albumins and uric acid levels were decreased in the gutkha and khaini users with no significant change in comparison with normal control subjects (Figure 5).

\section{Cotinine}

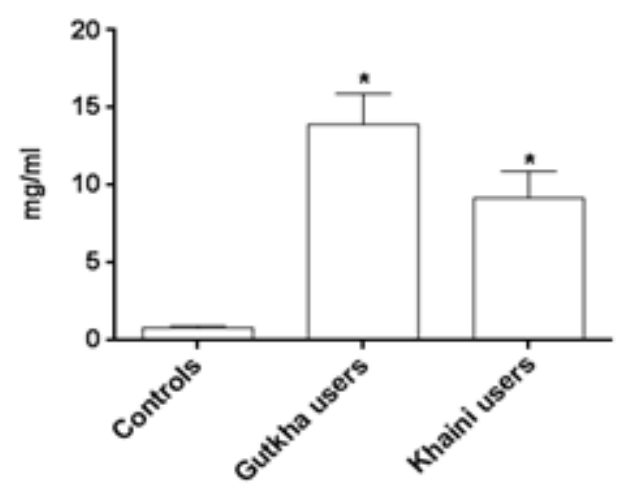

\section{Epinephrine}

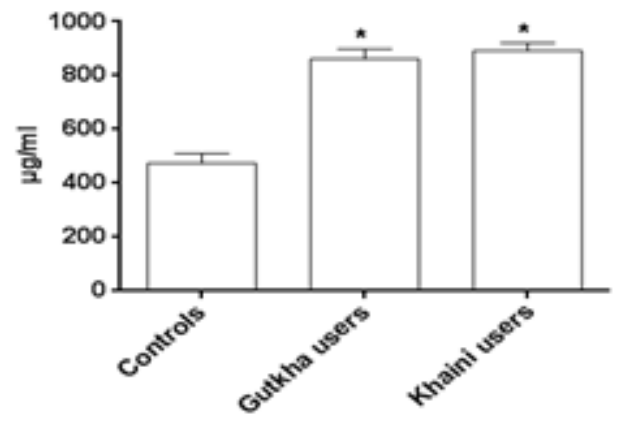

Figure I Urinary levels of nicotine, cotinine, and epinephrine in smokeless tobacco users.

Data are represented as the mean \pm SEM and $*$ indicates that data are statistically significant difference with the controls. 

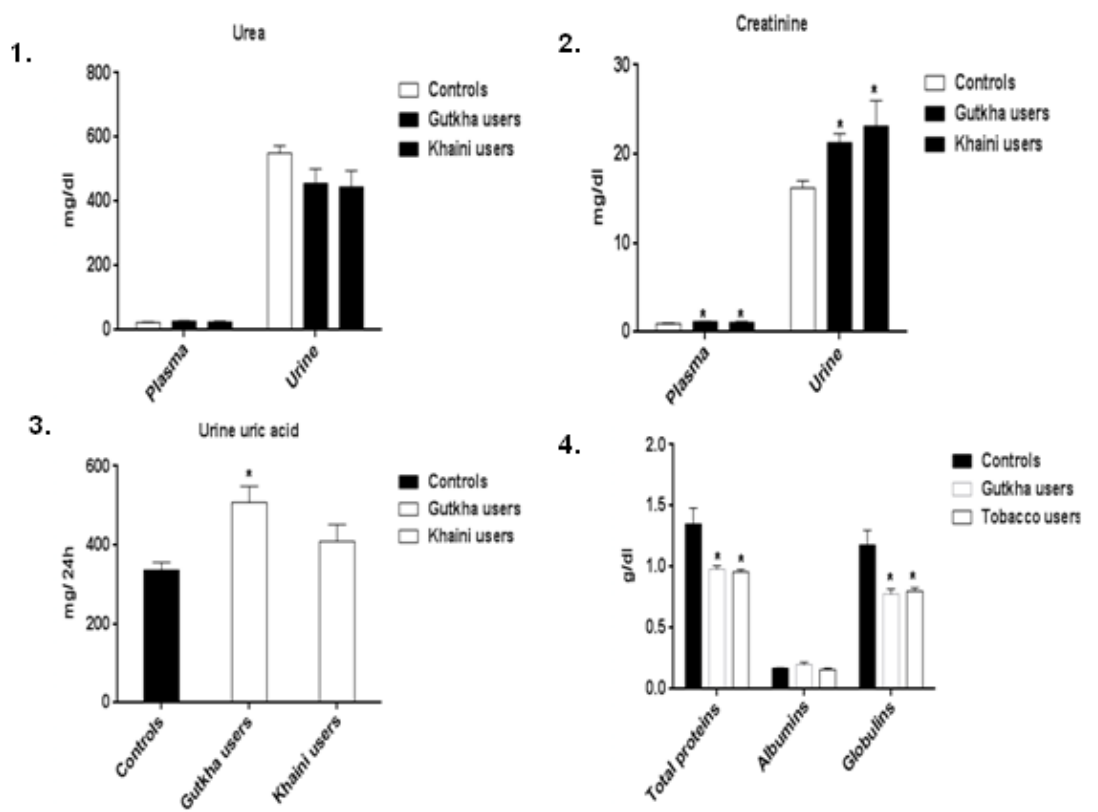

Figure 2 Effect of smokeless tobacco on urine biochemical profile.

Data are represented as the mean \pm SEM and * indicates that data are statistically significant difference with the controls.

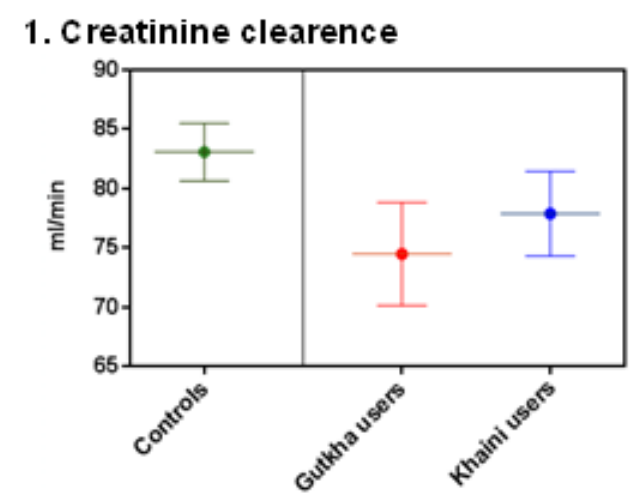

3. Protein-creatinine ratio

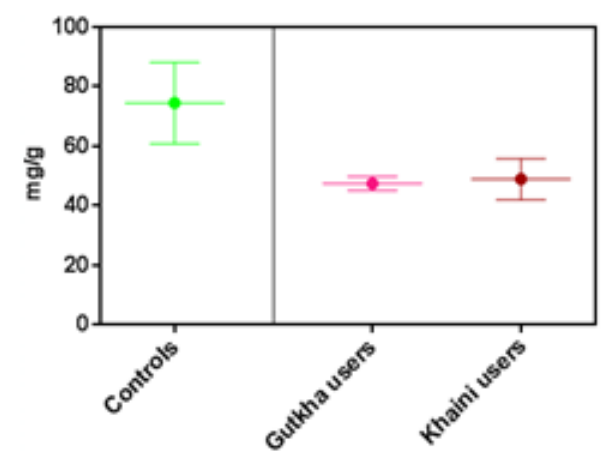

2. GFR

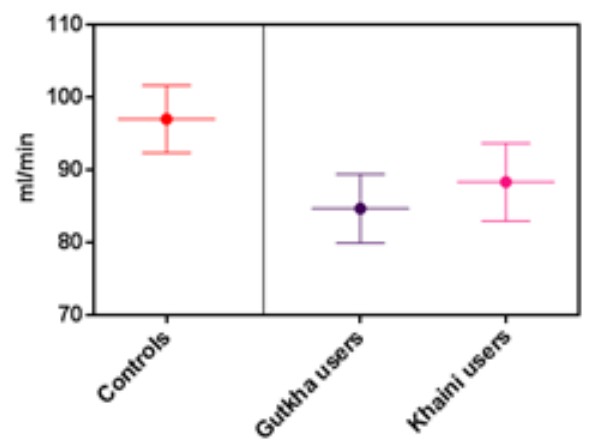

4. Urea clearence

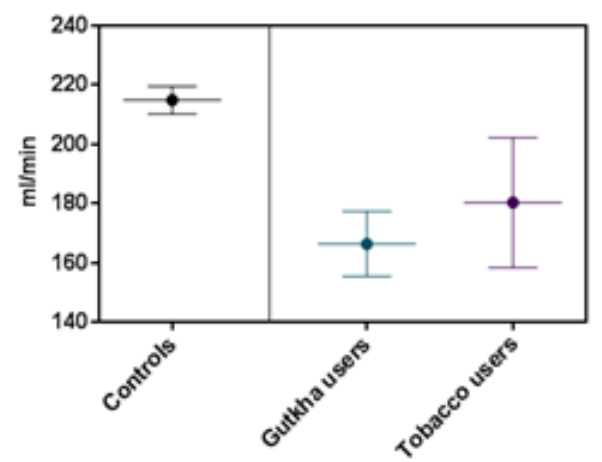

Figure 3 Smokeless tobacco induced kidney markers.

Data are represented as the mean \pm SEM and data are not statistically significant difference with the controls.

Note: GFR, glomerular filtration rate 
1. ACR

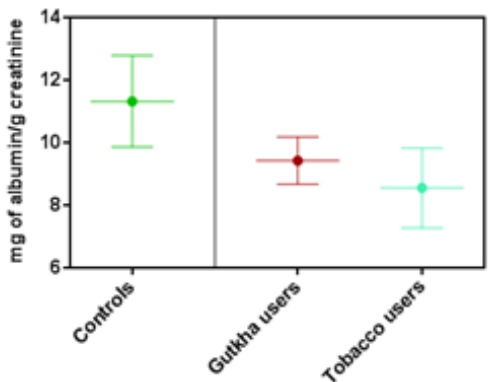

2. Lipid peroxidation

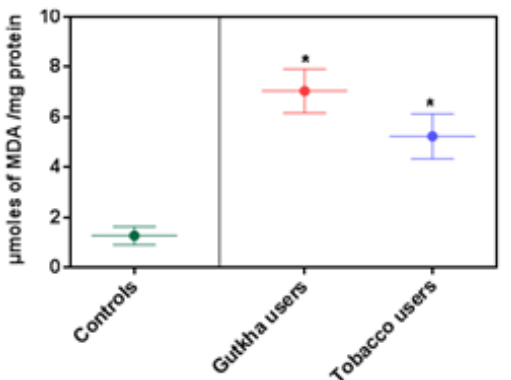

\section{Nitric oxide}

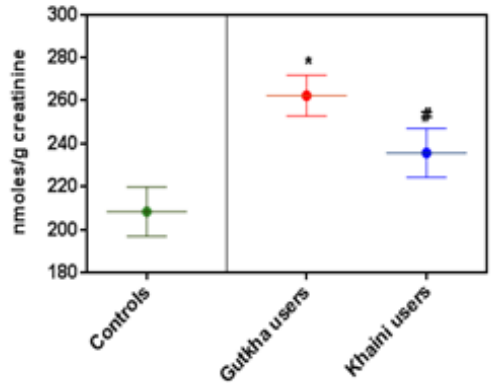

Figure 4 Concentrations of oxidative stress markers in urine of SLT users.

Data are represented as the mean \pm SEM and $*$ indicates data are statistically significant difference with the controls. \# indicates data are not statistically significant difference with the other groups.

Note:ACR, albumin creatinine ratio

\section{Total proteins}

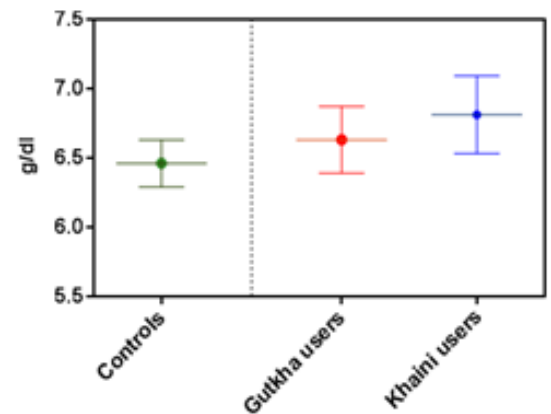

3. Globulins

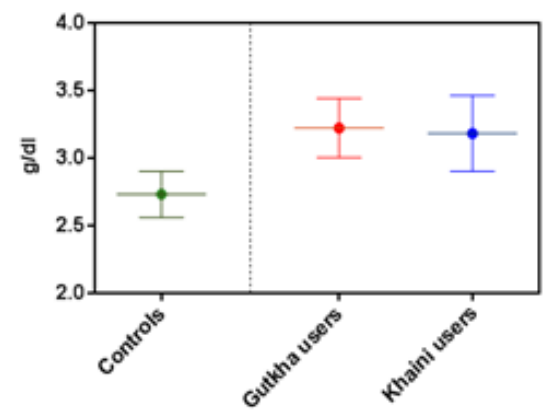

2. Albumins

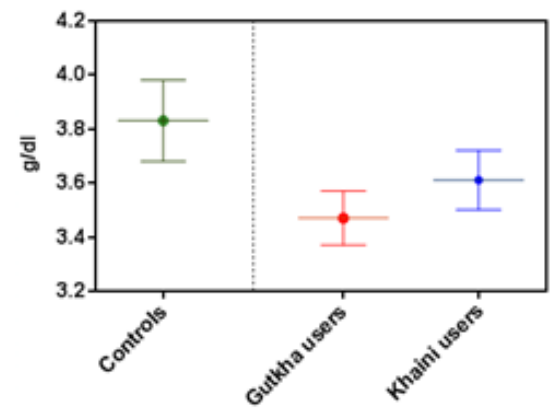

4. Uric acid

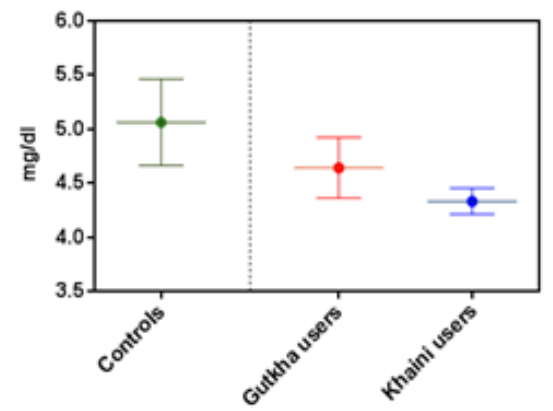

Figure 5 Levels of total proteins, albumins urea and uric acid in plasma.

Data are represented as the mean \pm SEM and data are statistically significant difference with the controls. 
HPLC chromatograms of nicotine, cotinine, and epinephrine in SLT users

The range of retention time of standard nicotine is $5.3-6.3 \mathrm{~min}$ and showed a chromatogram peak at $5.48 \mathrm{~min}$, whiles that standard cotinine between $3.6-4.6 \mathrm{~min}$ and showed a chromatogram peak at $4.05 \mathrm{~min}$. The normal control group had exposed to environmental tobacco smoke and some food constituents showed nicotine and cotinine levels. Further no peaks were observed in chromatograms of urine in normal controls with retention of 4.01 and $6.00 \mathrm{~min}$ of nicotine and cotinine, while gutkha consumers showed no nicotine chromatogram peak but showed cotinine peak at $4.29 \mathrm{~min}$. In these gutkha users, a large amount of nicotine was metabolized into cotinine (Figure 6).

Nicotine showed that chromatogram peak at $5.39 \mathrm{~min}$ retention time and cotinine showed at $3.77 \mathrm{~min}$ in khaini consumers (Figure 7). The range of retention time of standard epinephrine is 3.5-5.4min and showed a chromatogram peak at $3.60 \mathrm{~min}$. A small chromatogram peak observed at $3.91 \mathrm{~min}$ in gutkha consumers showed an epinephrine peak at $3.69 \mathrm{~min}$ and chromatogram peak at $4.33 \mathrm{~min}$ in khaini consumers (Figure 8).
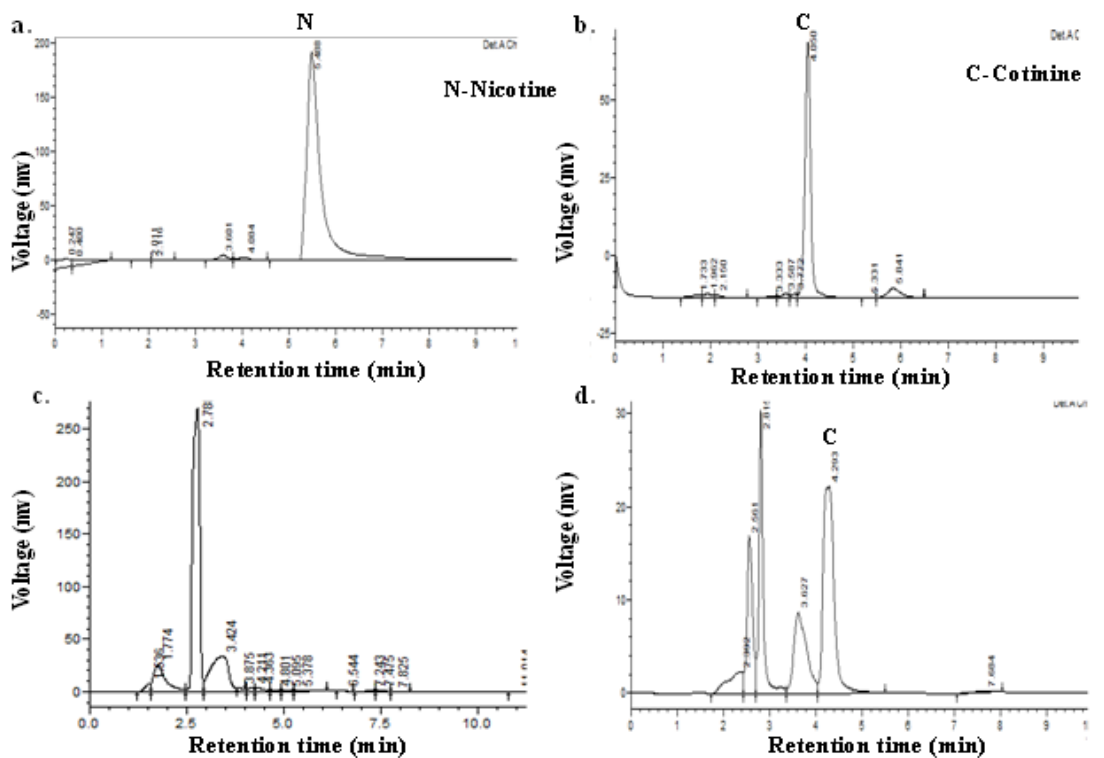

Figure 6 HPLC chromatograms of nicotine and cotinine.

a. Nicotine standard, b. Cotinine standard c. Control group d. Gutkha consumers.
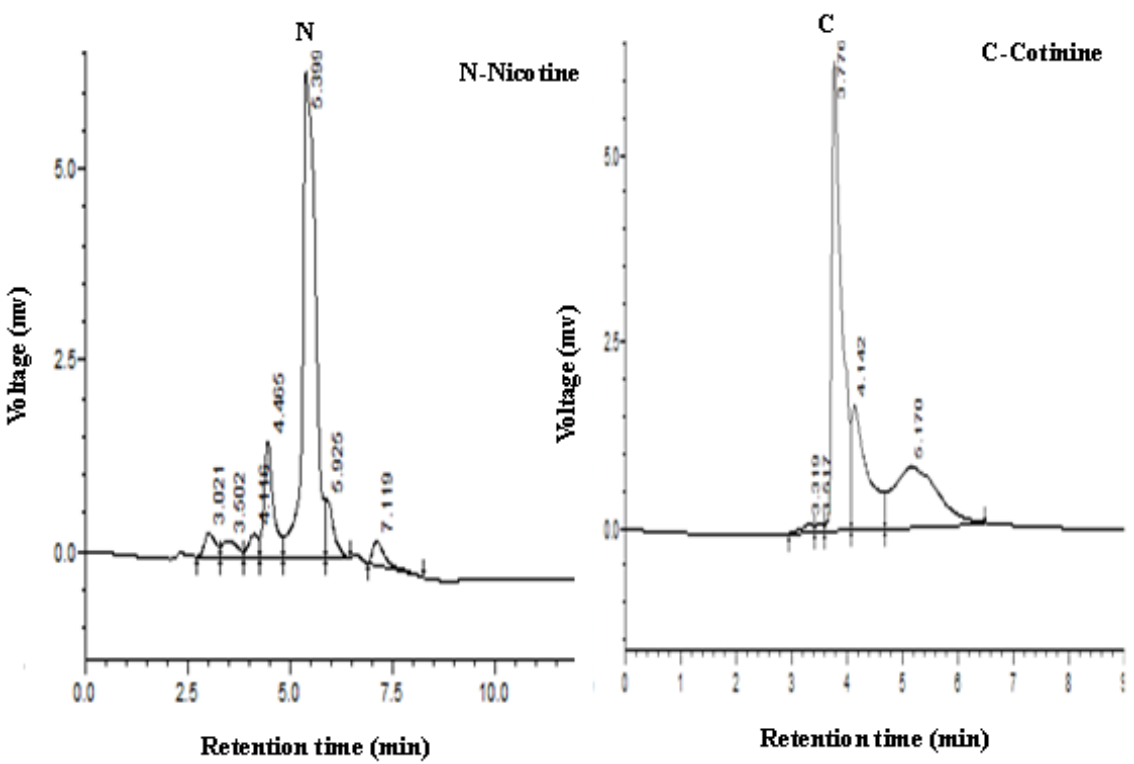

Figure 7 HPLC chromatograms of nicotine and cotinine in khaini users. 

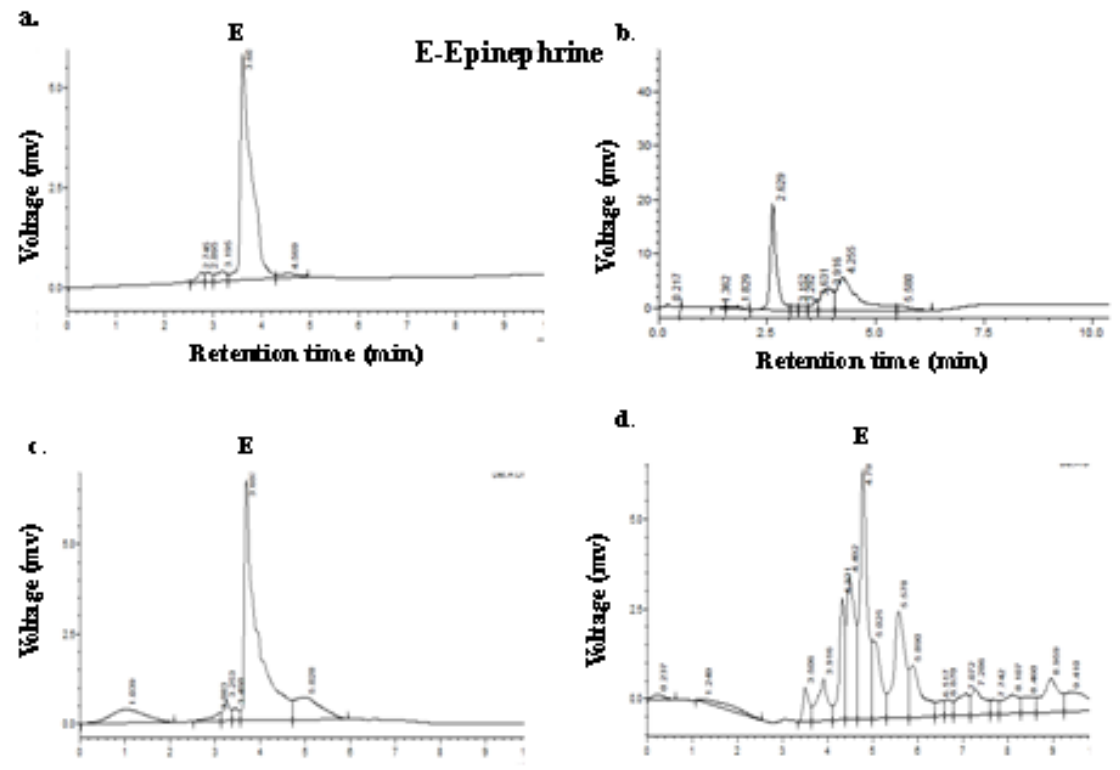

Reterion time (min)

Retention time (min)

Figure 8 HPLC chromatograms of epinephrine.

a: Epinephrine standard b: Control group c: Gutkha users d: Khaini users.

\section{Correlation analysis}

There was a strong uphill relationship of nicotine and cotinine with lipid peroxidation, nitric oxide, epinephrine, urea, creatinine and glomerular filtration rate in controls and smokeless tobacco consumers. In most cases, Pearson correlation coefficients were between 0.63 and 0.99 . There was no correlation of nicotine with uric acid in group I users and a weak negative correlation in group II users. There was a weak negative correlation of nicotine with total proteins in controls and khaini users, but in gutkha users, there was a moderate positive correlation. A weak negative correlation of nicotine with albumins in controls, gutkha users and khaini users was observed. There was a weak negative correlation of cotinine with uric acid in controls and weak positive in gutkha users. In khaini users, there was no correlation. There was a weak negative correlation of cotinine with total proteins in controls and group II users, but in group I users, there was a weak positive correlation. There was a weak negative correlation of cotinine with albumins in controls and khaini users, but in gutkha users there was no correlation. There were no significant differences of nicotine and cotinine with uric acid, total proteins and albumins (Table 1 \& Table 2).

Table I a Correlation matrix of nicotine with kidney markers

\begin{tabular}{lllll}
\hline Nicotine & \multicolumn{2}{l}{ Gutkha users } & \multicolumn{2}{l}{ Khaini users } \\
\hline & $\mathbf{r}$ & $\mathbf{P}$ & $\mathbf{r}$ & $\mathbf{P}$ \\
Urea & 0.68 & 0.0155 & 0.9 & $<0.000 \mathrm{I}$ \\
Creatinine & 0.9 & $<0.000 \mathrm{I}$ & 0.89 & $0.000 \mathrm{I}$ \\
Uric acid & -0.017 & 0.958 & -0.17 & 0.6004 \\
GFR & 0.86 & 0.0004 & 0.75 & 0.0047 \\
\hline
\end{tabular}

Table I b Correlation matrix of nicotine with oxidative stress parameters

\begin{tabular}{lllll}
\hline Nicotine & \multicolumn{2}{l}{ Gutkha users } & \multicolumn{2}{l}{ Khaini users } \\
\hline & $\mathbf{r}$ & $\mathbf{P}$ & $\mathbf{r}$ & $\mathbf{P}$ \\
Lipid peroxidation & 0.88 & 0.0002 & 0.84 & 0.0007 \\
Nitric oxide & 0.76 & 0.0044 & 0.86 & 0.0003 \\
Epinephrine & 0.63 & 0.0282 & 0.82 & 0.001 \\
Albumins & -0.14 & 0.6725 & -0.41 & 0.1907 \\
\hline
\end{tabular}

Table 2a Correlation matrix of cotinine with kidney markers

\begin{tabular}{lllll}
\hline Cotinine & \multicolumn{2}{l}{ Gutkha users } & \multicolumn{2}{l}{ Khaini users } \\
\hline & $\mathbf{r}$ & $\mathbf{P}$ & $\mathbf{r}$ & $\mathbf{P}$ \\
Urea & 0.94 & $<0.0001$ & 0.64 & 0.0246 \\
Creatinine & 0.98 & $<0.0001$ & 0.94 & $<0.0001$ \\
Uric acid & 0.13 & 0.6886 & -0.0095 & 0.9765 \\
GFR & 0.99 & $<0.0001$ & 0.66 & 0.0191
\end{tabular}

Table $\mathbf{2 b}$ Correlation matrix of cotinine with oxidative stress parameters

\begin{tabular}{llcll}
\hline Cotinine & \multicolumn{2}{l}{ Gutkha users } & \multicolumn{2}{l}{ Khaini users } \\
\hline & $\mathbf{r}$ & $\mathbf{P}$ & $\mathbf{r}$ & $\mathbf{P}$ \\
Lipid peroxidation & 0.96 & $<0.000 \mathrm{I}$ & 0.99 & $<0.000 \mathrm{I}$ \\
Nitric oxide & 0.94 & $<0.0001$ & 0.94 & $<0.000 \mathrm{I}$ \\
Albumins & -0.077 & 0.8121 & -0.31 & 0.3246 \\
Epinephrine & 0.92 & $<0.0001$ & 0.81 & 0.0013 \\
\hline
\end{tabular}

r, correlation coefficient; $P<0.000$ I, statistically significant difference 
Data on the distribution levels of nicotine and cotinine in group I, group II and group III users of urine samples are presented in Figure 9. The main metabolite of nicotine metabolism is cotinine, in addition to this, nicotine is extensively metabolized by the liver into other metabolites like 5' hydroxy cotinine, 5' hydroxy nicotine, nornicotine and nicotine iminium ion etc., (Figure 10). a. Nic otime
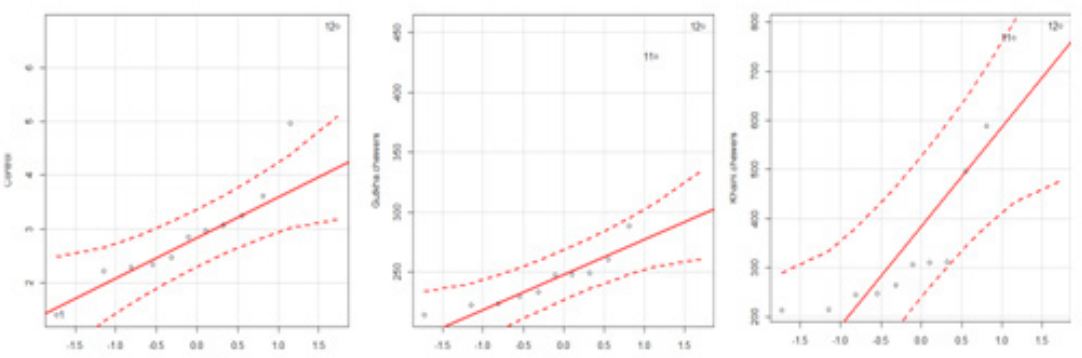

\section{b. Cotimine}
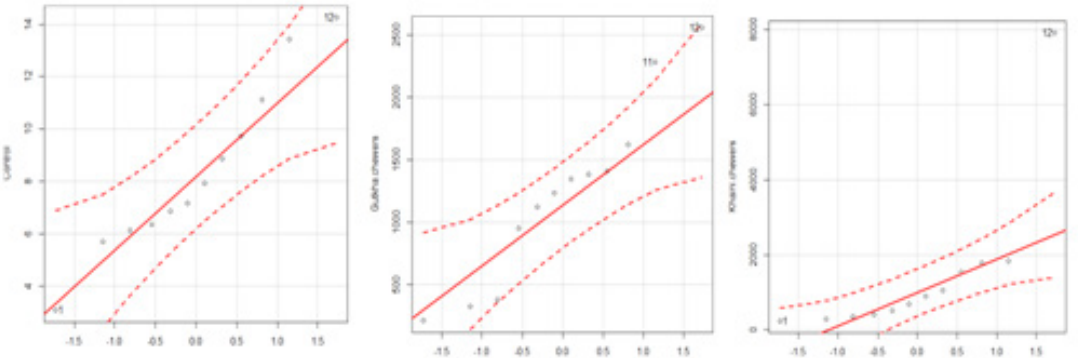

Figure 9 Quantile comparison plots of nicotine and cotinine levels in urine.<smiles>c1cncc([C@@H]2CCCN2)c1</smiles>

Nornicotine<smiles>CN1CCC[C@H]1c1cccnc1</smiles>
NICOTINE<smiles>C[N+]1=CCC[C@H]1c1cccnc1</smiles>

Nicotine- $\Delta^{17(5)}$-iminium lon<smiles>CN1C(=O)CC[C@H]1c1cccnc1</smiles>

Cotinine<smiles></smiles><smiles>C=C(C=NC)[C@H]1CCCN1C</smiles>

Nicotine Isomethonium lon

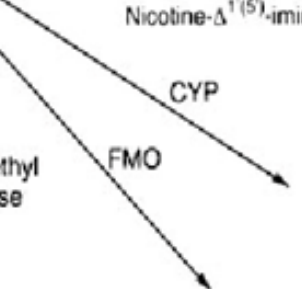<smiles>CN1CCCC1(O)c1cccnc1</smiles>

2.Hydroxynicotine<smiles>C[N+]1([O-])CCC[C@H]1c1cccnc1</smiles><smiles>C[N+]1([O-])CCC[C@H]1c1cccnc1</smiles>

$I^{\prime}(\mathbf{R})-2$ '(S)-cis Nicotine-N-oxide

Figure 10 The basic mechanism of nicotine metabolism. ${ }^{6,7}$ 


\section{Discussion}

The adverse effects of smokeless tobacco on renal function have gained more attention because it is associated with various diseases. The potential effects and dangers of SLT products in chronic kidney disease (CKD) are not clear. The approach we used to investigate the relationship of smokeless tobacco products and renal diseases is strong and can be an important risk factor for renal alterations. We have demonstrated an HPLC method for quantitative measurement of nicotine and its metabolite, cotinine in urine and smokeless tobacco was by far the most powerful predictor of renal functional deterioration. The major metabolite of nicotine metabolism is cotinine which acts as a qualitative marker of tobacco use and indicator of nicotine exposure. Urinary acidification has directly proportional increased the renal clearance and excretion of nicotine and in the same way urinary alkalinisation has inversely proportional to the renal clearance and nicotine excretion. ${ }^{17}$ The quantification of nicotine and cotinine in performed in plasma, saliva, and urine of smokeless tobacco consumers. Our study revealed that smokeless tobacco consumers had significantly elevated levels of nicotine and cotinine in the urine samples. Nicotine is found in vegetables such as potatoes, tomatoes, and eggplants in low levels. ${ }^{18}$ In a study of smokers, Matsukura et al. ${ }^{19}$ observed that the urinary excretion of nicotine increased significantly after smoking. Begum et al. ${ }^{20}$ reported that the gutkha and khaini users showed significantly increased levels of nicotine and cotinine in saliva. The long half life of cotinine could be useful for its detection measurement than nicotine and urinary $\mathrm{pH}$ has less influence on cotinine excretion. ${ }^{21}$ The difference of urine cotinine between smokers and non smokers was statistically significant. ${ }^{22}$ Adverse health consequences of smokeless tobacco would be expected to present a potential hazard. Nicotine acts as a potential indicator of reactive oxygen species via an increase in the synthesis of oxygen-derived free radicals. ${ }^{23}$ Cotinine is present in the blood higher than nicotine and concentrations of nicotine and cotinine in urine are tenfold to hundred fold greater than in plasma and saliva. ${ }^{24}$ Nicotine may enhance the sense of well-being, produce relaxation, help maintain vigilance, and reduce anxiety. ${ }^{21}$ Nicotine is a drug specific to smokeless tobacco users and can be used as a marker for the prevalence of smokeless tobacco use. Urinary nicotine and cotinine excretion showed a linear increase with degree of repeated tobacco exposure.

We observed that significantly increased excretion of epinephrine in smokeless tobacco users when compared to controls and with increasing consumption of smokeless tobacco, the concentration of epinephrine increased progressively. There was a significant increase in the urinary excretion of epinephrine during heavy smoking and nicotine increased the secretion of epinephrine by the adrenal glands. ${ }^{25,26}$ The concentration of cotinine depends on the original dose of nicotine exposure and there was a progressive increase in smokeless tobacco consumption which is associated with renal disease complications. Our results concluded that the gutkha and khaini users have elevated levels of nitric oxide in the urine. Nicotine could alter the activity of nitric oxide synthase (NOS) indirectly through production of oxygen-derived free radicals. ${ }^{27,28}$ Nitric oxide may be a physiological signaling molecule its high concentrations serve as a biomarker of health and disease ${ }^{29} \mathrm{NO}$ is synthesized by the enzyme inducible nitric oxide synthase (iNOS) and hence, involved in inflammatory processes and tumorogenesis. ${ }^{30,31}$ Malondialdehyde is the most abundant product formed during the process of lipid peroxidation and represents a potentially mutagenic and carcinogenic marker. ${ }^{32}$ Higher levels of malondialdehyde observed in the experimental subjects compared to healthy controls and nitric oxide as oxidative stress marker are due to the chronic exposure to smokeless tobacco which results in the greatest amount of reactive oxygen species production in cells and tissues. Previously published studies have established that smokers had significantly increased MDA levels in smokers than non-smokers. ${ }^{33}$

Smokeless tobacco is one of the renal risk factor and has negative impact on the renal function. Our data suggested that group I and group II users had increased excretion of epinephrine and epinephrine which stimulates platelet aggregation and thrombus formation by an adrenergic mechanism. ${ }^{34}$ Our study demonstrated that elevated levels of urine albumins in gutkha and khaini users than controls and decreased albumin creatinine ratio. Urinary albumin excretion is measured as albumin creatinine ratio and it reflects the vascular process which affects the glomeruli and albumin acts as an index of renal damage. ${ }^{35}$ Tobacco products lead to the risk of albuminuria in the general population and are early indicators for the progressive kidney damage.$^{36}$ It is conceivable that the relationship of smokeless tobacco to albuminuria indicates direct or indirect renal damage induced by chewing. Smokeless tobacco exerts potent effects on glomerular function by simultaneous decrease of GFR and creatinine clearance. The rate of decline in GFR is higher in smokers compared with nonsmokers and an elevated urinary albumin excretion rate was 2.8 -fold higher in smokers. ${ }^{37}$

The observed increase in the levels of uric acid excretion as reflected by the decreased concentrations in plasma of group I and group II users. A reduction in glomerular filtration rate will increment in the levels of uric acid. ${ }^{38,39}$ Uric acid has a direct and independent role in the pathogenesis of vascular disease, hypertension and in renal disease progression. ${ }^{39,40}$ The levels of creatinine are increased in both plasma and urine in gutkha and khaini users. An elevated level in the plasma and decreased levels of urine urea observed in group I and group II users compared to normal controls and also showed diminished levels of urea clearance has been demonstrated in experimental subjects. Urinary urea was inversely related to blood pressure and hypertension and is the main metabolite of nitrogen excretion. ${ }^{41}$ The determination of creatinine has been reported to be useful in evaluating the renal handling of uric acid as concentration of this parameter is highly dependent on endogenous production as well as on renal excretion. ${ }^{42}$ The mechanism by which tobacco products (either smoking or smokeless) have elevated the risk of renal disorders may be through enhancing the synthesis of free radicals which may result in alterations of glomerular function leading to elevated levels of urea and creatinine in tobacco chewers and smokers. ${ }^{43}$

Total proteins were decreased significantly in the urine as a concurrent increased levels observed in the plasma of smokeless tobacco users compared to controls. The protein creatinine ratio is an index of proteinuria which decreased in urine of gutkha and khaini users. Smokeless tobacco products decreased the excretion of proteins, urea and glomerular filtration which are accompanied by increased excretion of creatinine, uric acid and albumins in the users of smokeless tobacco. Negative impact of smoking on renal function contributes to the increased cardiovascular risk conferred by smoking. ${ }^{44}$ Biochemical measures of smokeless tobacco are increasingly used to detect the markers of kidney injuries and treatment of smokeless tobacco related diseases. Urinary lipid peroxidtion, nitric oxide, epinephrine, and kidney markers (Creatinine, urea, and glomerular filtration rate) are 
significantly and positively associated with smokeless tobacco. It is concluded that the gutkha and khaini exert potent and consistent effects on markers of oxidative stress which are accompanied by acute changes in renal hemodynamics and albuminuria.

\section{Conclusion}

The main finding of the present study is that, smokeless tobacco causes an acute decrease in GFR, urea, proteins, and creatinine clearance and increase in creatinine, uric acid, and albumins with parallel increase in nitric oxide and malondialdehyde and epinephrine excretion associated with sympathetic activation. Urinary nicotine and cotinine levels may be useful in predicting the risk of renal functional impairment. Glomerular filtration rate and urinary albumin, the early markers of chronic kidney diseases might serve as early and effective markers for consumption of smokeless tobacco in the humans. Mechanisms underlying the observed association need to be further characterized. Cessation of smokeless tobacco may be helpful in reducing the risk of renal diseases.

\section{Highlights}

a. Smokeless tobacco may able to cause an acute decrease in renal parameters in parallel with an increase in urinary nitric oxide, malondialdehyde levels, and epinephrine excretion associated with sympathetic activation.

b. Urinary nicotine and cotinine measurements may be useful in predicting the risk of renal functional impairment in the smokeless tobacco consumers.

c. Increased levels of the markers of oxidative and nitrosative stress indicate the nicotine acts as sensitive marker of production of reactive oxygen species.

d. A strong linear relationship of smokeless tobacco products and renal risk and cessation of smokeless tobacco may be helpful to reduce the risk of renal diseases.

\section{Funding}

The authors received no financial support for the research, authorship, and/or publication of this article.

\section{Acknowledgments}

None.

\section{Conflicts of interest}

The authors report no declaration of interest and no conflict of interest.

\section{References}

1. Kumar NMV, Khijmatgar S, Chowdhury C. Interrelations of Level of Urinary Cotinine and Score for Fagerstrom Test for Nicotine Dependence among Beedi Smokers and Smokeless Tobacco Users in India. Indian J Psychol Med. 2017;39(4):392-398.

2. Smokeless Tobacco and Public Health: A Global Perspective. National Cancer Institute and Centres for Disease Control and Prevention. 2014.

3. Dwivedi S, Aggarwal A, Dev M. All in the name of flavour, fragrance \& freshness: Commonly used smokeless tobacco preparations in and around a tertiary hospital in India. Indian J Med Res. 2012;136(5):836-841.
4. Sunanda P, Panda B, Dash C, et al. Prevalence of abnormal spermatozoa in tobacco chewing sub fertile males. J Hum Reprod Sci. 2014;7(2):136142.

5. Benowitz NL, Hukkanen J, Jacob P. Nicotine chemistry, metabolism, kinetics and biomarkers. Handb Exp Pharmacol. 2009;192:29-60.

6. Hukkanen J, Jacob P, Benowitz NL. Metabolism and disposition kinetics of nicotine. Pharmacol Rev. 2005;57(1):79-115.

7. Von Weymarn LB, Retzlaff C, Murphy SE. CYP2A6- and CYP2A13catalyzed metabolism of the nicotine $\Delta 5^{\prime}\left(1^{\prime}\right)$ iminium ion. $J$ Pharmacol Exp Ther. 2012;343(2):307-315.

8. Benowitz NL. Cotinine as a biomarker of environmental tobacco smoke exposure. Epidemiol Rev. 1996;18(2):188-204.

9. Pryor WA, Stone K. Oxidants in cigarettes smoke. Radicals, hydrogen peroxide, peroxynitrate, and peroxynitrite. Ann $N$ Y Acad Sci. 1993;686:12-27.

10. Ensafi AA, Dadkhah M, Karimi-Maleh H. Determination of isoproterenol and uric acid by voltammetric method using carbon nanotubes paste electrode and p-chloranil. Colloids Surf B Biointerfaces. 2011;84(1):148154.

11. Behera D, Uppal R, Majumdar S. Urinary levels of nicotine and cotinine in tobacco users. Indian J Med Res. 2003;118:129-133.

12. Varley H, Gowenlock AH, Bell M. Immunological methods in Practical Clinical Biochemistry. William Heinemann Medical Books. 1980;562163.

13. Sastry KVH, Moudgal RP, Mohan J, et al. Spectrophotometric determination of serum nitrite and nitrate by Copper-Cadmium alloy. Ana Biochem. 2002;306(1):79-82.

14. Buege JA, Aust SD. Microsomal lipid peroxidation. Methods Enzymol. 1978;52:302-310.

15. Massadeh AM, Gharaibeh AA, Omari KW. A single-step extraction method for the determination of nicotine and cotinine in jordanian smokers' blood and urine samples by RP-HPLC and GC-MS. J Chromatogr Sci. 2009;47(2):170-177.

16. Mishra A, Upadhyay A, Patra A, et al. Simultaneous determination of epinephrine and norepinephrine by high performance liquid chromatography. Sci pharma. 2009;77:367-374.

17. Benowitz NL, Jacob P. Nicotine renal excretion rate influences nicotine intake during cigarette smoking. J Pharmacol Exp Ther. 1985;234(1):153155 .

18. Siegmund B, Leitner E, Pfannhauser W. Determination of the nicotine content of various edible nightshades (Solanaceae) and their products and estimation of the associated dietary nicotine intake. J Agric Food Chem. 1999;47(8):3113-3120

19. Matsukura S, Sakamoto N, Takahashi K, et al. Effect of pH and urine flow on urinary nicotine excretion after smoking cigarette. Clin Pharmacol Ther. 1979;25(5):549-554.

20. Begum SF, Nagajothi G, Latha KS, et al. Possible role of nicotine and cotinine on nitroxidative stress and antioxidant content in saliva of smokeless tobacco consumers. Pract Lab Med. 2018;12:e00105.

21. Benowitz NL, Porchet H, Sheiner L, et al. Nicotine absorption and cardiovascular effects with smokeless tobacco use: comparison with cigarettes and nicotine gum. Clin Pharmacol Ther. 1988;44(1):23-28.

22. Jung S, Lee IS, Kim SB, et al. Urine cotinine for assessing tobacco smoke exposure in Korean: Analysis of the korea national health and nutrition examination survey (KNHANES). Tuberc Respir Dis. 2012;73(4):210 218 
23. Mayhan WG, Sharpe GM. Superoxide dismutase restores endotheliumdependent arteriolar dilatation during acute infusion of nicotine. $J \mathrm{Appl}$ Physiol. 1998;85(4):1292-1298.

24. Jarvis M, Tunstall-Pedoe H, Feyerabend C, et al. Biochemical markers of smoke absorption and self reported exposure to passive smoking. $J$ Epidemiol Community Health. 1984;38(4):335-339.

25. Watts DT. The effect of nicotine and smoking on the secretion of epinephrine. Ann N Y Acad Sci. 1960;90:74-80.

26. Zuspan FP. The effect of smoking and oral contraceptives on the urinary excretion of epinephrine and norepinephrine. Am J Obstet Gynecol. 1979;135(8):1012-1015.

27. Mayhan WG, Sharpe GM. Chronic exposure to nicotine alters endotheliumdependent arteriolar dilatation: effect of superoxide dismutase. $J \mathrm{Appl}$ Physiol. 1999;86(4):1126-1134.

28. Tonnessen BH, Severson SR, Hurt RD, et al. Modulation of nitric-oxide synthase by nicotine. J Pharmacol Exp Ther. 2000;295(2): 601-606.

29. Zhou H, Zou B, Hazucha M, et al. Nasal nitric oxide and life style exposure to tobacco smoke. Ann Otol Rhinol Laryngol. 2011;120(7):455-459.

30. Beckman JS, Beckman TW, Chen J, et al. Apparent hydroxyl radical production by peroxynitrite: Implications for endothelial injury from nitric oxide and superoxide. Proc Natl Acad Sci U S A. 1990;87(4):1620-1624.

31. Preethi S, Jose JI, Sivapathasundharam B, et al. Evaluation of salivary nitric oxide levels in smokers, tobacco chewers and patients with ora lichenoid reactions. J Clin Diagn Res. 2016;10(1):63-66.

32. Plastaras JP, Riggins JN, Otteneder M, et al. Reactivity and mutagenecity of endogenous DNA oxopropenylating agents: base propenals, malondialdehyde, and N (epsilon)-oxopropenyllysine. Chem Res Toxicol. 2000;13(12):1235-1242.

33. Lykkesfeldt J. Malondialdehyde as biomarker of oxidative damage to lipids caused by smoking. Clin Chim Acta. 2007;380(1-2):50-58.
34. Folts JD, Bonebrake FC. The effects of cigarette smoke and nicotine on platelet thrombus formation in stenosed dog coronary arteries: inhibition with phentolamine. Circulation. 1982;65(3):465-470.

35. Deckert T, Feldt-Rasmussen B, Borch-Johnsen K, et al. Albuminuria reflects widespread vascular damage. The Steno hypothesis. Diabetologia. 1989;32(4):219-226.

36. Shah T, Purohit G. Microproteinuria in chronic smokers as a predictor of renal diseases: A case control study. Biochemical Research. 2013; 24(1):55-58.

37. Orth SR. Smoking and the Kidney. J Am Soc Nephrol. 2002;13(6):16631672.

38. Sorensen LB. Role of the intestinal tract in the elimination of uric acid. Arthritis Rheum. 1965;8(5):694-706.

39. Kanellis J, Feig DI, Johnson RJ. Does asymptomatic hyperuricaemia contribute to the development of renal and cardiovascular disease? An old controversy renewed. Nephrology. 2004;9(6):394-399.

40. Johnson RJ, Kang DH, Feig D, et al. Is there a pathogenetic role for uric acid in hypertension and cardiovascular and renal disease? Hypertension. 2003;41(6):1183-1190.

41. Cirillo M, Lombardi C, Laurenzi M, et al. Relation of urinary urea to blood pressure: interaction with urinary sodium. J Hum Hypertens. 2002;16(3):205-212.

42. Haj Mouhamed D, Ezzaher A, Neffati F, et al. Effect of cigarette smoking on plasma uric acid concentrations. Environ Health Prev Med. 2011;16(5):307-312.

43. Christiansen JS. Cigarette smoking and prevalence of micro angiopathy in juvenile-onset insulin-dependent diabetes mellitus. Diabetes Care. 1978;1:146-149.

44. Orth SR. Cigarette smoking: an important renal risk factor far beyond carcinogenesis. Tob Induc Dis. 2003;1(2):11. 